\title{
Article \\ Prognosis of Laboratory-Confirmed Influenza and Respiratory Syncytial Virus in Acute Heart Failure
}

\author{
David Carballo ${ }^{1}$, Nicolas Garin ${ }^{2}$, Jérôme Stirnemann ${ }^{2} \oplus$, Aline Mamin ${ }^{3}$, Virginie Prendki ${ }^{3}$, Philippe Meyer ${ }^{1}$, \\ Christophe Marti ${ }^{2}$, Francois Mach ${ }^{1}$, Jean-Luc Reny ${ }^{2}$, Jacques Serratrice ${ }^{2}$, Laurent Kaiser ${ }^{3}$ \\ and Sebastian Carballo ${ }^{2, *}$ \\ 1 Service of Cardiology, Department of Medicine, Geneva University Hospitals, 1211 Geneva, Switzerland; \\ david.carballo@hcuge.ch (D.C.); philippe.meyer@hcuge.ch (P.M.); francois.mach@hcuge.ch (F.M.) \\ 2 Service of General Internal Medicine, Department of Medicine, Geneva University Hospitals, \\ 1211 Geneva, Switzerland; nicolas.garin@hcuge.ch (N.G.); jerome.stirnemann@hcuge.ch (J.S.); \\ christophe.marti@hcuge.ch (C.M.); jean-luc.reny@hcuge.ch (J.-L.R.); jacques.serratrice@hcuge.ch (J.S.) \\ 3 Service of Infectious Diseases, Department of Medicine, Geneva University Hospitals, \\ 1211 Geneva, Switzerland; aline.mamin@hcuge.ch (A.M.); virginie.prendki@hcuge.ch (V.P.); \\ laurent.kaiser@hcuge.ch (L.K.) \\ * Correspondence: sebastian.carballo@hcuge.ch
}

check for updates

Citation: Carballo, D.; Garin, N.; Stirnemann, J.; Mamin, A.; Prendki, V.; Meyer, P.; Marti, C.; Mach, F.; Reny, J.-L.; Serratrice, J.; et al. Prognosis of Laboratory-Confirmed Influenza and Respiratory Syncytial Virus in Acute Heart Failure. J. Clin. Med. 2021, 10, 4546. https://doi.org/10.3390/ jcm10194546

Academic Editor: Laurent Fauchier

Received: 27 July 2021

Accepted: 24 September 2021

Published: 30 September 2021

Publisher's Note: MDPI stays neutral with regard to jurisdictional claims in published maps and institutional affiliations.

Copyright: (c) 2021 by the authors. Licensee MDPI, Basel, Switzerland. This article is an open access article distributed under the terms and conditions of the Creative Commons Attribution (CC BY) license (https:/ / creativecommons.org/licenses/by/ $4.0 /)$.

\begin{abstract}
Concomitant respiratory viral infections may influence clinical outcomes of acute decompensated heart failure (ADHF) but this association is based on indirect observation. The aim of this study was to evaluate the prevalence and impact of laboratory-confirmed influenza or respiratory syncytial virus (RSV) infection on outcomes in patients hospitalised for ADHF. Prospective cohort of patients hospitalised for ADHF with systematic influenza and RSV screening using real-time PCR on nasopharyngeal swabs. The primary outcome was all-cause mortality or readmission at 90 days. Among 803 patients with ADHF, 196 (24.5\%) patients had concomitant flu-like symptoms of influenza. PCR was positive in 45 patients ( 27 for influenza, 19 for RSV). At 90 days, PCR positive patients had lower rates of all-cause mortality or readmission as compared to patients without flu-like symptoms (HR 0.40, 95\% CI 0.18-0.91, $p=0.03$ ), and non-significantly less all-cause mortality (HR $0.30,95 \%$ CI 0.04-2.20, $p=0.24$ ), or HF-related death or readmission (HR 0.36, 95\% CI 0.13-0.99, $p=0.05$ ). The prevalence of influenza or RSV infection in patients admitted for ADHF was low and associated with less all-cause mortality and readmission. Concomitant viral infection with ADHF may not in itself be a predictor of poor outcomes. (ClinicalTrials.gov NCT02444416).
\end{abstract}

Keywords: acute heart failure; influenza; RSV

\section{Introduction}

Acute decompensated heart failure (ADHF) is a leading cause of hospitalization and mortality in patients older than 65 years and prognosis remains poor [1-3]. Influenza epidemics impact both general population mortality rates and number of hospitalizations [4,5] Prognosis of heart failure (HF) is associated with factors such as age, renal function, blood pressure, left ventricular ejection fraction (LVEF), B-type natriuretic peptide (BNP) levels and certain common comorbidities [6-10]. Influenza has been considered another factor that could impact the clinical outcome of HF. However both the prevalence of influenza and its impact on outcomes have been insufficiently studied in patients with ADHF [11-14]. In a retrospective analysis of a national registry of patients hospitalised with influenza, $20 \%$ had concomitant HF but diagnosis of influenza was only based on International Classification of Diseases codes [12]. Furthermore, it has been suggested that patients with HF have a greater risk of hospitalization during the influenza season, the latter also characterized by an increase in the incidence of infections linked to other respiratory viruses [13-15]. Respiratory viruses such as respiratory syncytial virus (RSV), may affect cardiovascular 
outcomes in ADHF but have also been poorly evaluated [16]. Whilst influenza-like illness is a recognized syndrome, the association of laboratory confirmed influenza or RSV infection using polymerase chain reaction (PCR) with outcomes of patients hospitalised for ADHF has not previously been addressed [17].Influenza and RSV are the most common viral infections during seasonal epidemics and often have similar clinical presentations. Furthermore, these infections are seldomly microbiologically confirmed. The purpose of this study was therefore to evaluate both the prevalence and the impact of laboratory confirmed influenza and RSV disease on clinical outcomes in patients with ADHF.

\section{Materials and Methods}

\subsection{Patients}

Patients admitted for ADHF to the Department of medicine at the University Hospitals of Geneva between November 2014 and May 2019 were included. Patients were defined as having ADHF if they were hospitalised principally with symptoms and signs of HF, elevated natriuretic peptides (b-type natriuretic peptide [BNP] levels $>100 \mathrm{ng} / \mathrm{L}$, or Nterminal-pro-BNP [NT-pro-BNP] levels $>300 \mathrm{ng} / \mathrm{L}$ ), and structural and/or functional abnormality on echocardiography based on the European Society of Cardiology (ESC) criteria $[7,18]$. For patients with a left ventricular ejection fraction (LVEF) $<40 \%$, no additional echocardiographic criterion was used. For patients with a LVEF $\geq 40 \%$, at least one of the following additional echocardiographic criteria had to be met: left atrial volume index $(\mathrm{LAVI})>34 \mathrm{~mL} / \mathrm{m}^{2}$, left ventricular mass index (LVMI) $\geq 115 \mathrm{~g} / \mathrm{m}^{2}$ for males and $\geq 95 \mathrm{~g} / \mathrm{m}^{2}$ for females, or diastolic dysfunction defined as an $\mathrm{E} / \mathrm{e}^{\prime} \geq 13$ and a mean $\mathrm{e}^{\prime}$ septal and lateral wall $<9 \mathrm{~cm} / \mathrm{s}$. The protocol was approved by the institutional ethics committee (protocol CER 14-019, ClinicalTrials.gov NCT02444416), and all patients gave written informed consent.

The University Hospital of Geneva is the main surveillance center for seasonal viral infection and harbors the national reference laboratory. Viral screening is conducted for both epidemiological and communicable disease prevention policies. Year round testing is carried out with peak systematic viral screening on all patients with flu-like symptoms during the influenza season, as defined by the Swiss Federal Office of Public Health (FOPH). Symptoms prompting screening include fever, rhinitis, cough and myalgia, new onset of one or more respiratory symptoms or worsening of a chronic condition involving respiratory symptoms. Screening is carried out with PCR on nasopharyngeal or oropharyngeal swabs (NPS). The FOPH publishes weekly and annual reports of cases of influenza based on a sentinel surveillance system that documents the number of consultations for flu like symptoms [19]. The epidemic threshold is defined as 69 cases per 100,000 populations [19]. Both influenza and RSV having similar clinical presentations and we therefore analysed the impact of these combined documented viral infections.

In this study, collected data included age, gender, weight, smoking status, a full medical history and medical therapy at admission, throughout hospital stay and at discharge. Clinical presentation was also recorded at admission and throughout hospital stay and including New York Heart Association (NYHA) dyspnea class, and clinical parameters, such as blood pressure, heart rate, and weight. Customary investigations were carried out on all patients, including full blood count, urea and electrolytes, electrocardiography, and echocardiography. Echocardiography was analyzed by experienced staff cardiologists. Patients were classified according to ESC guidelines as having heart failure with either reduced ejection fraction (LVEF) (HFrEF) if left ventricular ejection fraction (LVEF) was $<40 \%$, mid-range ejection fraction (HFmrEF) if LVEF was between $40 \%$ and $49 \%$, or preserved ejection fraction (HFpEF) if LVEF was $\geq 50 \%$ [7].

Respiratory viral infections are punctual events and often have short term implications, and therefore the impact on clinical outcomes of concomitant viral infection was assessed at 90 days. Patients were prospectively followed via their contact with treating physicians and the examination of hospital medical records. Follow-up data included mortality, readmission, clinical state, and medication. 
The primary outcome was a composite of all-cause mortality or readmission at 90 days. Secondary outcomes were all cause mortality, as well as heart failure related mortality and readmission at 90 days. Death or readmission were considered as being due to heart failure, if the primary cause was linked to heart failure. Patients were categorized either symptomatic, with flu like symptoms, or without suggestive symptoms. Patients with flu-like symptoms during the influenza season were considered as being PCR positive or PCR negative based on results of PCR for Influenza A, Influenza B or RSV.

\subsection{Nucleic Acid Analysis Using Multiplex Real-Time PCR}

The NPS were performed on symptomatic individuals during the initial hospitalization. These were placed in COPAN ${ }^{\circledR} 305$ Universal Transport Medium (COPAN Italia spa, Brescia, Italy) and processed directly in the central virology laboratory. Nucleic acids were extracted with Qiasymphony (Qiagen, Hombrechtikon, Switzerland) using a Virus/Pathogen kit (937055, Qiagen). Real-time polymerase chain reaction (RT-PCR) was performed on a Viia7 thermocycler (Life Technologies, Carlsbad, California, USA). The FTD Respiratory pathogens panel (FTD-2, FastTrack Diagnostics, Esch-sur-Alzette, Switzerland) was used to target viruses including influenza A, A (H1N1) pdm2009 and B viruses and respiratory syncytial virus.

\subsection{Statistical Analysis}

We used mean for continuous data, and number (\%) for categorical data, as appropriate. ANOVA tests were used for comparing quantitative data, and Chi-square or Fischer test for categorical comparisons. Survival analysis with Log-Rank test was used for the unadjusted analysis, Kaplan-Meier plots, and Cox proportional hazard models for multivariate exploration. The multivariate model included variables that were associated with outcome on unadjusted analysis $(p<0.2)$, as well as recognized variables identified in previous studies such as age, gender, diabetes, chronic obstructive pulmonary disease (COPD), kidney disease, anaemia, hypertension [20]. Statistical analysis was performed using the SPSS statistical software package, (version 25.1).

\section{Results}

Of 803 patients hospitalised with ADHF, 196 presented flu-like symptoms of influenza and underwent NPS. PCR was positive in 45 patients of which 27 were positive for influenza influenza (20 Influenza A and 7 Influenza B) and 19 were positive for RSV; 1 patient was positive for both Influenza and RSV. Mean age in the cohort was 77 years and was similar in patients with and without flu-like symptoms (Table 1). Baseline characteristics including gender, body mass index (BMI), LVEF were comparable across all groups. History of chronic obstructive pulmonary disease (COPD) was more present in the virus tested groups. With respect to clinical presentation, those who had a positive viral PCR had more severe dyspnea and higher temperature at admission, but other features such as blood pressure and heart rate were similar. C-reactive protein was higher in the tested groups, irrespective of PCR positivity. There was no significant differences in NT-proBNP, hemoglobin or leucocyte count between the groups. Heart failure medication was similar across the groups.

Of the 151 patients with flu-like symptoms who were PCR negative, concomitant respiratory or infectious diseases was documented in 79 of them (52.3\%). There were 49 radiologically confirmed pneumonias, 12 acute exacerbations of COPD, 7 other acute respiratory conditions ( 1 pulmonary embolism, 1 exacerbation of bronchiectasis, 3 non-specific interstitial pneumonias (NSIP), 1 idiopathic pulmonary fibrosis, 1 interstitial pneumonia attributed to amiodarone toxicity), and 11 infections or inflammatory conditions. 
Table 1. Baseline characteristics.

\begin{tabular}{|c|c|c|c|c|}
\hline & \multicolumn{2}{|c|}{ Symptomatic Patients $(\mathrm{N}=196)$} & \multirow{2}{*}{$\begin{array}{c}\text { Patients without } \\
\text { Suggestive Symptoms } \\
\text { N }(\%)(\mathrm{N}=607)\end{array}$} & \multirow[b]{2}{*}{$p$} \\
\hline & $\begin{array}{c}\text { PCR positive } \\
\mathrm{N}(\%) \\
(\mathrm{N}=45)\end{array}$ & $\begin{array}{c}\text { PCR negative } \\
N(\%) \\
(N=151)\end{array}$ & & \\
\hline Age (mean (SD)) & $77.9( \pm 10.3)$ & $77.1( \pm 10.2)$ & $77.2( \pm 11.2)$ & 0.93 \\
\hline Sex & & & & 0.49 \\
\hline Male & $23(51)$ & $84(56)$ & $354(58)$ & \\
\hline Female & $22(48)$ & $67(44)$ & $253(42)$ & \\
\hline $\mathrm{BMI}\left(\mathrm{Kg} / \mathrm{m}^{2}\right)$ & $27.8(6.0)$ & $27.7(7.2)$ & $26.5(6.3)$ & 0.09 \\
\hline $\begin{array}{l}\text { Left ventricular ejection } \\
\text { fraction }\end{array}$ & & & & 0.71 \\
\hline Preserved $(>50 \%)$ & $23(55)$ & $81(57)$ & $322(54)$ & \\
\hline Mid-range (40-49\%) & $8(19)$ & $18(13)$ & $77(13)$ & \\
\hline Reduced $(<40 \%)$ & $11(26)$ & $43(30)$ & $198(33)$ & \\
\hline \multicolumn{5}{|l|}{ Comorbidities } \\
\hline Hypertension & $34(76)$ & $121(80)$ & $482(19)$ & 0.03 \\
\hline Diabetes & $17(39)$ & $44(29)$ & $197(33)$ & 0.43 \\
\hline Chronic kidney disease & $19(48)$ & $58(39)$ & $205(36)$ & 0.29 \\
\hline COPD & $9(21)$ & $35(24)$ & $70(12)$ & $<0.001$ \\
\hline Atrial fibrillation & $21(47)$ & $70(47)$ & $276(47)$ & 0.99 \\
\hline Anaemia & $21(47)$ & $62(41)$ & $245(40)$ & 0.06 \\
\hline \multicolumn{5}{|l|}{ Etiology of heart failure } \\
\hline Ischaemic & $15(33.3)$ & $57(37.7)$ & $192(31.6)$ & 0.05 \\
\hline Hypertensive & $11(24.4)$ & $40(26.5)$ & $123(20.3)$ & 0.03 \\
\hline Valvular & $13(28.9)$ & $29(19.2)$ & $128(21.1)$ & 0.05 \\
\hline Arythmic & $16(34.8)$ & $50(33.3)$ & $180(29.7)$ & 0.07 \\
\hline Active smoking & $10(22)$ & $23(15)$ & $102(17)$ & 0.55 \\
\hline NYHA class & & & & 0.01 \\
\hline I & 0 & $1(1)$ & $6(1)$ & \\
\hline II & $3(7)$ & $9(6)$ & $35(6)$ & \\
\hline III & $6(13)$ & $45(31)$ & $219(39)$ & \\
\hline IV & $36(80)$ & $90(62)$ & $296(53)$ & \\
\hline De novo heart failure & $9(20)$ & $43(29)$ & $204(34)$ & 0.21 \\
\hline \multicolumn{5}{|l|}{ Parameters (mean (SD)) } \\
\hline Systolic blood pressure & $143( \pm 28)$ & $137( \pm 25)$ & $142( \pm 27)$ & 0.12 \\
\hline Diastolic blood pressure & $77( \pm 18)$ & $77( \pm 16)$ & $83( \pm 20)$ & 0.003 \\
\hline Heart rate & $92( \pm 21)$ & $95( \pm 59)$ & $90( \pm 25)$ & 0.19 \\
\hline Temperature $\left({ }^{\circ} \mathrm{C}\right)$ & $37.3( \pm 0.9)$ & $36.9( \pm 0.8)$ & $36.8( \pm 0.6)$ & $<0.001$ \\
\hline Fever $\left(>38^{\circ} \mathrm{C}\right) \mathrm{N}(\%)$ & $10(22.2)$ & $14(9.3)$ & $22(3.6)$ & $<0.001$ \\
\hline $\mathrm{BNP}(n=123)$ & $1549( \pm 1520)$ & $1264( \pm 1563)$ & $1150( \pm 1021)$ & 0.53 \\
\hline NT-proBNP $(n=678)$ & $7752( \pm 12060)$ & $8979( \pm 12302)$ & $8187( \pm 11091)$ & 0.76 \\
\hline $\mathrm{Hb}(\mathrm{g} / \mathrm{L})$ & $125( \pm 26)$ & $123( \pm 23)$ & $124( \pm 23)$ & 0.75 \\
\hline
\end{tabular}


Table 1. Cont.

\begin{tabular}{|c|c|c|c|c|}
\hline & Symptor & $(\mathrm{N}=196)$ & $\begin{array}{c}\text { Patients without } \\
\text { Suggestive Symptoms } \\
\text { N }(\%)(\mathrm{N}=607)\end{array}$ & \\
\hline eGFR (mL/min) & $51( \pm 23)$ & $53( \pm 22)$ & $53( \pm 24)$ & 0.77 \\
\hline $\mathrm{CRP}(n=786)$ & $48( \pm 64)$ & $55( \pm 74)$ & $24( \pm 43)$ & $<0.001$ \\
\hline Leucocytes & $8.7( \pm 3.6)$ & $12.6( \pm 26.7)$ & $10.6( \pm 19.6)$ & 0.43 \\
\hline \multicolumn{5}{|c|}{ Medication at admission } \\
\hline $\mathrm{ACEi}$ & $11(24)$ & $42(28)$ & $166(27)$ & 0.52 \\
\hline ARB & $19(42)$ & $40(27)$ & $177(29)$ & 0.19 \\
\hline Loop diuretics & $24(51)$ & $88(58)$ & $268(44)$ & 0.07 \\
\hline Betablockers & $24(53)$ & $80(53)$ & $342(56)$ & 0.52 \\
\hline MRA & $5(11)$ & $20(13)$ & $79(13)$ & 0.99 \\
\hline \multicolumn{5}{|c|}{ Medication at discharge } \\
\hline ACEi & $16(36)$ & $63(42)$ & $231(38)$ & 0.96 \\
\hline ARB & $9(20)$ & $29(19)$ & $138(23)$ & 0.86 \\
\hline Loop diuretics & $35(78)$ & $114(76)$ & $445(73)$ & 0.19 \\
\hline Betablockers & $30(67)$ & $97(64)$ & 417 (69) & 0.82 \\
\hline MRA & $6(13)$ & $21(14)$ & $110(18)$ & 0.34 \\
\hline
\end{tabular}

BMI: body mass index, COPD: chronic obstructive pulmonary disease, NYHA: New York Heart Association, BNP: Brain natriuretic peptide, $\mathrm{Hb}$ : hemoglobin, eGFR: estimated glomerular filtration rate, ACEi: angiotensin converting enzyme inhibitors, ARB: angiotensin II receptor blockers, MRA: mineralocorticoid receptor antagonist, HF: heart failure, PCR: polymerase chain reaction.

\section{Survival Analysis}

In survival analysis at 90 days, patients hospitalised for ADHF who were PCR positive for influenza or RSV, had fewer combined rates of all-cause mortality or readmission (HR $0.44,95 \%$ CI $0.21-0.93, p=0.03$ ), and non-significantly less all-cause mortality (HR $0.31,95 \%$ CI $0.42-2.23, p=0.24$ ), or HF related death or readmission (HR $0.44,95 \%$ CI $0.18-1.07, p=0.07$ ) (Table 2 (unadjusted) and Table 3, Figure 1), as compared to patients without flu-like symptoms. PCR-negative patients had a trend toward higher all-cause mortality or readmission rates (HR 1.14, 95\% CI 0.85-1.54, $p=0.38$ ) and had higher all-cause mortality rates (HR 2.27, 95\% CI 1.28-3.73, $p=0.001$ ) as compared to patients without flu-like symptoms. There was also a trend for HF related death or readmission (HR 1.15, 95\% CI 0.81-1.64, $p=0.07$ ) and increased HF related death (HR 2.00 95\% CI 1.08-3.71, $p=0.03$ ) (Table 3, Figure 1). Overall, at 90 days there were 69 all-cause deaths, 262 all-cause deaths or readmissions, 47 heart failure related deaths, and 191 heart failure related deaths or readmissions. Survival analysis for the primary endpoint was similar when influenza and RSV were considered separately (HR 0.41, 95\% CI 0.15-1.11, $p=0.08$ and HR $0.44,95 \%$ CI $0.14-1.37, p=0.16$ respectively). Variables that were included in the multivariate analysis included viral PCR status, as well as age, sex, BMI, hypertension COPD, diabetes, chronic kidney disease, chronic anaemia and LVEF $(<40 \%)$ either because of significant association on univariate analysis, or because they are established predictors of outcome [8]. 
Table 2. Unadjusted analysis of association with 90 day all-cause mortality and readmission.

\begin{tabular}{ccc} 
& $\begin{array}{c}\text { All-Cause Mortality or } \\
\text { Readmission (HR (95\% CI) }\end{array}$ & $p$ Value \\
\hline Sex (male) & $1.10(0.86-1.40)$ & 0.46 \\
Age, year & $1.00(0.99-1.01)$ & 0.70 \\
BMI, Kg/m ${ }^{2}$ & $0.99(0.97-1.01)$ & 0.42 \\
Hypertension & $1.14(0.84-1.56)$ & 0.40 \\
COPD & $1.72(1.27-2.33)$ & $<0.001$ \\
Diabetes & $1.13(0.87-1.46)$ & 0.36 \\
Chronic kidney disease & $1.25(0.97-1.61)$ & 0.08 \\
Chronic anemia & $1.25(0.98-1.60)$ & 0.08 \\
LVEF $(<40 \%)^{\text {a }}$ & $0.94(0.73-1.22)$ & 0.66 \\
\hline
\end{tabular}

a As compared to preserved LVEF. HR: Hazard ratio, LVEF: left ventricular ejection fraction, BMI: body mass index, COPD: chronic obstructive pulmonary disease.

Table 3. Association of viral testing status with 90 day clinical outcomes expressed as hazard ratios in symptomatic patients as compared to patients without flu-like symptoms.

\begin{tabular}{|c|c|c|c|c|}
\hline & \multicolumn{4}{|c|}{ Symptomatic Patients } \\
\hline & \multicolumn{2}{|c|}{$\begin{array}{l}\text { PCR Positive Patients } \\
\text { HR * }(95 \% \text { CI }) p \text { Value }\end{array}$} & \multicolumn{2}{|c|}{$\begin{array}{l}\text { PCR Negative Patients } \\
\text { HR * }(95 \% \text { CI }) p \text { Value }\end{array}$} \\
\hline & Unadjusted & Adjusted & Unadjusted & Adjusted \\
\hline \multirow{3}{*}{$\begin{array}{l}\text { All-cause } \\
\text { mortality or } \\
\text { readmission }\end{array}$} & 0.44 & 0.40 & 1.14 & 1.11 \\
\hline & $(0.21-0.93)$ & $(0.18-0.91)$ & $(0.85-1.54)$ & $(0.80-1.53)$ \\
\hline & 0.03 & 0.03 & 0.38 & 0.66 \\
\hline \multirow{3}{*}{$\begin{array}{l}\text { All-cause } \\
\text { mortality }\end{array}$} & 0.31 & 0.30 & 2.27 & 2.41 \\
\hline & $(0.42-2.23)$ & $(0.04-2.20)$ & $(1.28-3.73)$ & $(1.40-4.15)$ \\
\hline & 0.24 & 0.24 & 0.001 & $<0.01$ \\
\hline \multirow{3}{*}{$\begin{array}{l}\text { Heart failure } \\
\text { related mortality } \\
\text { or readmission }\end{array}$} & 0.44 & 0.36 & 1.13 & 1.16 \\
\hline & $(0.18-1.07)$ & $(0.13-0.99)$ & $(0.70-1.60)$ & $(0.80-1.68)$ \\
\hline & 0.07 & 0.05 & 0.51 & 0.44 \\
\hline \multirow{3}{*}{$\begin{array}{l}\text { Heart failure } \\
\text { related mortality }\end{array}$} & 0.44 & 0.43 & 2.02 & 2.00 \\
\hline & $(0.06-3.19)$ & $(0.06-3.20)$ & $(1.09-3.74)$ & $(1.01-3.96)$ \\
\hline & 0.41 & 0.41 & 0.03 & 0.05 \\
\hline
\end{tabular}

HR: Hazard ratio *as compared to patients without flu-like symptoms. The model was adjusted for age, sex chronic obstructive pulmonary disease, chronic kidney disease, chronic anaemia, hypertension, diabetes and left ventricular ejection fraction.

In multivariate adjusted analysis, PCR positive patients also had less all-cause mortality or readmission (HR $0.40,95 \%$ CI $0.18-0.91, p=0.03$ ) as well as less HF related death or readmission as compared to patients without flu-like symptoms (HR 0.36, 95\% CI 0.13-0.99, $p=0.05$ ) (Table 3). As in univariate analysis, PCR negative patients, showed a trend towards higher all-cause mortality and readmission (HR 1.11, 95\% CI 0.80-1.53, $p<0.66$ ) (Table 2), as well as increased all-cause mortality (HR 2.41, 95\% CI 1.40-4.15, $p<0.01$ ) as compared to patients without flu-like symptoms.

A history of chronic obstructive pulmonary disease (COPD) was associated with increased all-cause death and readmission (HR 1.70, 95\% CI 1.23-2.36, $p<0.01$ ), as well increased heart failure related death or readmission (HR 1.84, 95\% CI 1.27-2.67, $p<0.01$ ).

Of the 27 patients with laboratory confirmed influenza infection, 17 received oseltamivir. Interaction variables were tested between oseltamivir use and virus testing categories and were non-significant. ( $p=0.348$ for death or readmission, $p=0.608$ for death) but this study is underpowered to fully address this issue. 
A. Survival without all-cause mortality or readmission

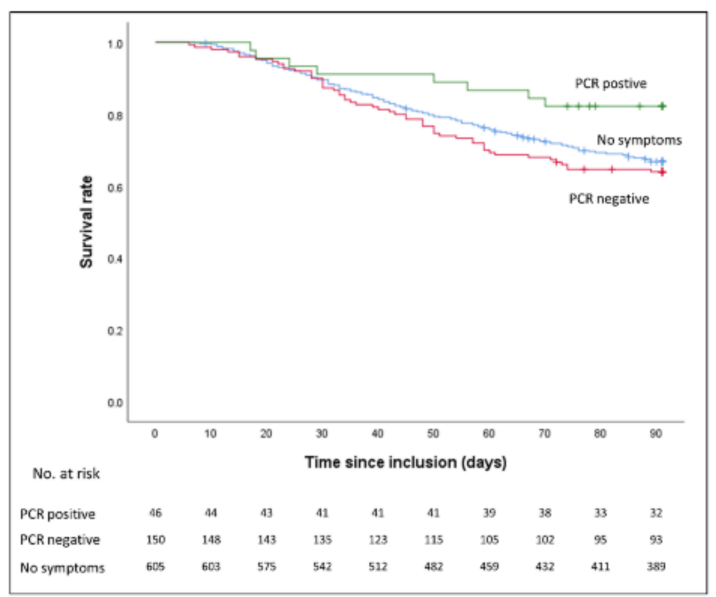

C. Survival without heart failure related mortality or readmission

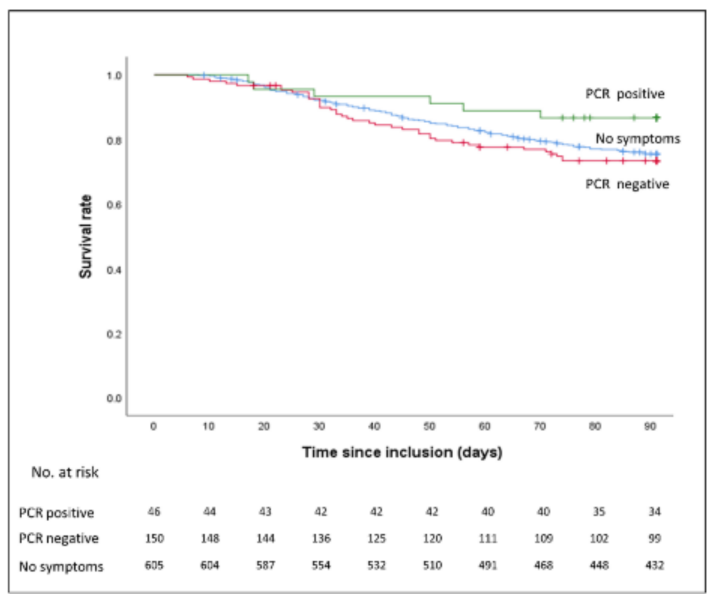

B. Survival without all-cause mortality

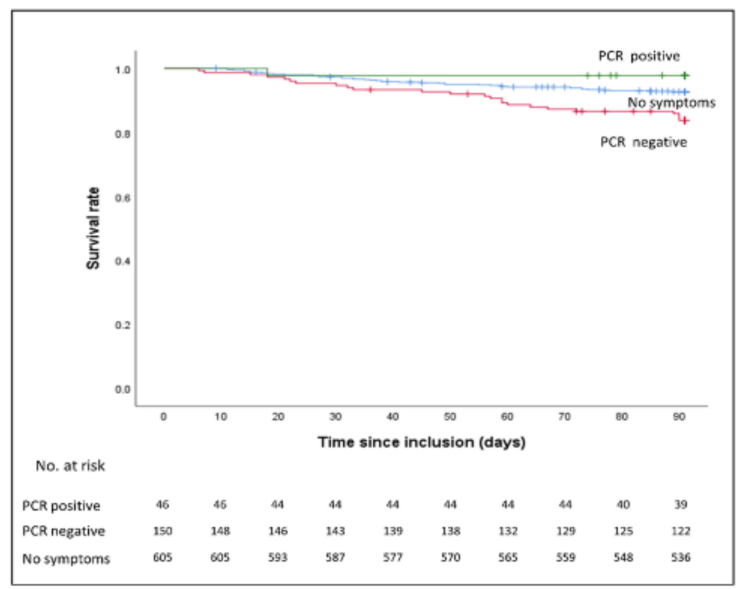

D. Survival without heart failure related mortality

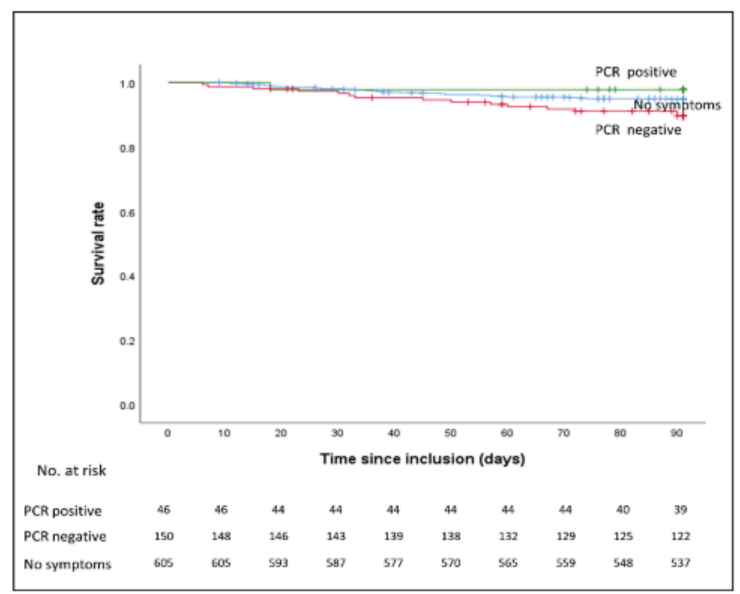

Figure 1. Kaplan-Meier survival analysis for 90-day clinical endpoints based on Influenza and respiratory syncytial virus (RSV) testing. Green: PCR positive, Red: PCR negative, Blue: patients without flu-like symptoms (no symptoms). (A). Survival without all-cause mortality or readmission, (B). Survival without all-cause mortality, (C). Survival without heart failure related mortality or readmission, (D). Survival without heart failure related mortality.

\section{Discussion}

In patients admitted for ADHF, the prevalence of concomitant PCR confirmed influenza or RSV infection was low, even in symptomatic patients during the influenza seasons. Furthermore, these cases were associated with less all-cause and HF-related mortality or hospital readmission at 90 days. Patients who were PCR negative for viral infection had comparatively higher rates of clinical outcomes. In this population, concomitant viral infection with ADHF was not in itself a predictor or marker of poor outcomes. Our study is the first to our knowledge to prospectively evaluate the impact of concomitant PCR proven influenza and RSV infection in patients hospitalised for ADHF.

The association between and viral infection and heart failure has been documented epidemiologically. Pathophysiologically, infections including those with influenza and RSV, increase metabolic demands. Patients with heart failure have decreased circulatory reserve and, as in our cohort and others, are often elderly with multiple comorbidities [21]. These patients may not be able to meet these increased metabolic needs when infected. Furthermore the severity of infection and the specific increased burden may explain variation in outcomes [11]. The burden of influenza and RSV has previously been estimated but determining the total burden is complex because the attributable mortality depends on death categories [22]. Underlying respiratory or circulatory deaths are severely impacted by these viral infections. However, as in other studies, the precise definition of circulatory 
deaths and or the means for viral infection determination are often not described. In our cohort, documented viral infection was not associated with worse outcome. Several hypotheses may explain this unanticipated association of PCR-influenza or RSV infection with fewer clinical outcomes in ADHF, even if the baseline prognostic variables do not seem to indicate that patients with PCR-confirmed influenza or RSV where at lesser risk. This group had a well-defined potential viral infectious trigger of decompensation in comparison with patients with no flu-like symptoms, in whom the triggers may have been more diverse and may have played a role in the poor outcomes. In our study, ADHF patients with flu-like symptoms and PCR negative for influenza and RSV had increased rates of clinical outcomes. Although confirming bacterial infection in respiratory disease such as pneumonia is notoriously difficult, we suggest that the worse outcome in patients who tested negatively may be due to more severe respiratory disease, such as bacterial pneumonia [23-25]. In our cohort, of the patients who tested negative, $53 \%$ had conditions such as documented pneumonia, COPD exacerbation or acute respiratory conditions.

Although there is evidence that influenza affects patients with HF, this is mostly based on indirect evidence from studies that use diagnostic codes and seasonal epidemiological data to show this association, but which do not strictly define criteria for either HF or influenza infection. Stronger association is demonstrated between influenza and other cardiovascular disease such as myocardial infarction [26]. A retrospective case control, propensity matched study based on an inpatient database showed that in all-cause hospitalizations, patients with HF and concomitant influenza infection had a higher rate of in-hospital mortality rate and respiratory complications [27]. In a similarly designed case control study of patients hospitalised with influenza, an association was shown between the comorbid presence of HF and increased in-hospital mortality [12]. In another retrospective cohort, the influenza-attributable risk of hospitalization among adults with congestive HF was increased during the influenza season [14]. The manner in which the influenza season is defined can also influence this estimation [13]. Further evidence for the association of influenza and poor outcomes in patients with HF derives from observations that influenza vaccination is associated with a reduced risk of both all-cause and cardiovascular death [11]. In our cohort, although some patients with proven influenza or RSV infection may have respiratory symptoms that may be mistaken for heart failure, we feel this to be a minimal source of misdiagnosis because all fulfilled the most recent HFrEF and HFpEF diagnostic criteria with a HFA-PEFF score $\geq 5$, including high BNP levels [18]. Our results, based on definitive HF and PCR confirmed viral infection, provides a more robust evaluation of the association between these diseases.

With respect to RSV, few studies have addressed the impact of infection in patients with heart failure [16]. Indirect evidence suggests that concomitant RSV infection may be present in 13 to $20 \%$ of patients, but these studies of temporally related diagnoses lack clear definitions of heart failure and methods for RSV diagnosis [28,29]. In our study only $2.7 \%$ of patients with heart failure and respiratory symptoms had PCR confirmed RSV infection.

In our study, a history of COPD was associated with worse clinical outcomes. HF and COPD share common risk factors and several studies suggest a prevalence of concurrent HF and COPD of between $10 \%$ and $40 \%$ [30,31]. Concurrent COPD has previously been shown to independently predict mortality in patients with HFrEF as well as HFpEF [10,30-32].

Screening for viral infection in hospitalised patients has epidemiological value, however, in our cohort, proven influenza or RSV infection was not associated with a worse prognosis. When considering the clinical implications, despite routine screening for influenza, the prevalence of influenza infection in patients admitted with ADHF was lower than previously estimated. Furthermore, whether targeted antiviral therapy has an impact in these cases is not known. The retrospective report mentioned earlier, using linked data for nationwide registries, suggested that influenza vaccination is associated with a reduced risk of all-cause and cardiovascular death in patients with heart failure but precise characteristics of the heart failure status were not available in that report and confounding 
by indication maybe an issue [11]. Vaccination status is not readily available in clinical files and not routinely collected, and was therefore not available in our cohort.

One limitation of our study is the presence of residual confounding because of its observational nature, and our findings are therefore limited to association and not causality. Other limitations include the single centre nature of the cohort and the sample size. However, our hospital is the principle primary care structure for a large population basin and therefore manages most cases of decompensated HF. The proportion of patients with a LVEF $<50 \%$ was $44 \%$, and with HFrEF defined as LVEF $<40 \%$ was just over $31 \%$. This is similar to figures of other cohorts of acute heart failure [33]. In our cohort, the proportion of patients with ischaemic heart disease was about $35 \%$, also similar to published figures in other cohorts [34]. Although we have no information about the exact percentage of vaccinated patients in our cohort, seasonal influenza vaccination of the elderly population in Switzerland is estimated at approximately $40 \%$ [35]. How this level of vaccination impacts outcomes is unclear. Although survival analysis for the primary endpoint was similar when influenza and RSV were considered separately, the number of events was small. These results merit verification in a larger cohort. A strength however of our study was the systematic PCR screening of patients with flu-like symptoms, although molecular testing has performance limitations linked to sensitivity and specificity characteristics [36]. Further strengths are its prospective design and the use of robust clinical and biological inclusion criteria based on accepted guidelines and definitions for the identification of patients with HF [7,9]. The cohort corresponds to a real-life representation of patients hospitalised with ADHF, characterized by frequent comorbidities, which may allow its results to be generalizable to a larger population.

\section{Conclusions}

In patients admitted for ADHF, prevalence of concomitant influenza or RSV infection was low and associated with less all-cause mortality and readmission at 90 days. Concomitant viral infection with ADHF may not in itself be a predictor of poor outcomes. Studies in larger cohorts are needed to further clarify the precise nature of this relationship.

Author Contributions: Conceptualization, S.C., N.G. and D.C.; Data curation, J.S. (Jérôme Stirnemann) and A.M.; Formal analysis, S.C., D.C. and J.S. (Jérôme Stirnemann); Investigation, D.C., S.C. and J.S. (Jérôme Stirnemann); Methodology, S.C., N.G. and D.C.; Writing-original draft, D.C. and S.C.; Writing-review and editing, L.K., N.G., P.M., C.M., V.P., J.-L.R., J.S. (Jacques Serratrice), F.M., D.C. and J.S. (Jérôme Stirnemann) All authors have read and agreed to the published version of the manuscript.

Funding: This research received no external funding.

Institutional Review Board Statement: The study was conducted according to the guidelines of the Declaration of Helsinki, and approved by the Institutional Review Board (or Ethics Committee) of the Commission cantonale d'éthique de la recherche (CCER) de Genève (protocol code: CER 14-019; date of approval: 28 November 2014).

Informed Consent Statement: Informed consent was obtained from all subjects involved in the study.

Data Availability Statement: The data presented in this study are available on request from the corresponding author.

Conflicts of Interest: The authors declare no conflict of interest.

\section{References}

1. Jhund, P.S.; Macintyre, K.; Simpson, C.R.; Lewsey, J.D.; Stewart, S.; Redpath, A.; Chalmers, J.W.; Capewell, S.; McMurray, J.J. Long-term trends in first hospitalization for heart failure and subsequent survival between 1986 and 2003: A population study of 5.1 million people. Circulation 2009, 119, 515-523. [CrossRef] [PubMed]

2. Levy, D.; Kenchaiah, S.; Larson, M.G.; Benjamin, E.J.; Kupka, M.J.; Ho, K.K.; Murabito, J.M.; Vasan, R.S. Long-term trends in the incidence of and survival with heart failure. N. Engl. J. Med. 2002, 347, 1397-1402. [CrossRef] [PubMed] 
3. Roger, V.L.; Go, A.S.; Lloyd-Jones, D.M.; Benjamin, E.J.; Berry, J.D.; Borden, W.B.; Bravata, D.M.; Dai, S.; Ford, E.S.; Fox, C.S.; et al. Executive summary: Heart disease and stroke statistics-2012 update: A report from the American Heart Association. Circulation 2012, 125, 188-197. [CrossRef] [PubMed]

4. Simonsen, L.; Clarke, M.J.; Williamson, G.D.; Stroup, D.F.; Arden, N.H.; Schonberger, L.B. The impact of influenza epidemics on mortality: Introducing a severity index. Am. J. Public Health 1997, 87, 1944-1950. [CrossRef] [PubMed]

5. Simonsen, L.; Fukuda, K.; Schonberger, L.B.; Cox, N.J. The impact of influenza epidemics on hospitalizations. J. Infect. Dis. 2000, 181, 831-837. [CrossRef] [PubMed]

6. Berra, G.; Garin, N.; Stirnemann, J.; Jannot, A.S.; Martin, P.Y.; Perrier, A.; Carballo, S. Outcome in acute heart failure: Prognostic value of acute kidney injury and worsening renal function. J. Card. Fail. 2015, 21, 382-390. [CrossRef]

7. Ponikowski, P.; Voors, A.A.; Anker, S.D.; Bueno, H.; Cleland, J.G.F.; Coats, A.J.S.; Falk, V.; Gonzalez-Juanatey, J.R.; Harjola, V.P.; Jankowska, E.A.; et al. 2016 ESC Guidelines for the diagnosis and treatment of acute and chronic heart failure: The Task Force for the diagnosis and treatment of acute and chronic heart failure of the European Society of Cardiology (ESC)Developed with the special contribution of the Heart Failure Association (HFA) of the ESC. Eur. Heart J. 2016, 37, 2129-2200. [CrossRef]

8. Rahimi, K.; Bennett, D.; Conrad, N.; Williams, T.M.; Basu, J.; Dwight, J.; Woodward, M.; Patel, A.; McMurray, J.; MacMahon, S. Risk prediction in patients with heart failure: A systematic review and analysis. JACC Heart Fail. 2014, 2, 440-446. [CrossRef]

9. Yancy, C.W.; Jessup, M.; Bozkurt, B.; Butler, J.; Casey, D.E., Jr.; Drazner, M.H.; Fonarow, G.C.; Geraci, S.A.; Horwich, T.; Januzzi, J.L.; et al. 2013 ACCF/AHA guideline for the management of heart failure: Executive summary: A report of the American College of Cardiology Foundation/American Heart Association Task Force on practice guidelines. Circulation 2013, 128, 1810-1852. [CrossRef]

10. Flattet, Y.; Garin, N.; Serratrice, J.; Perrier, A.; Stirnemann, J.; Carballo, S. Determining prognosis in acute exacerbation of COPD. Int. J. Chron. Obstruct. Pulmon. Dis. 2017, 12, 467-475. [CrossRef]

11. Modin, D.; Jorgensen, M.E.; Gislason, G.; Jensen, J.S.; Kober, L.; Claggett, B.; Hegde, S.M.; Solomon, S.D.; Torp-Pedersen, C.; Biering-Sorensen, T. Influenza Vaccine in Heart Failure. Circulation 2019, 139, 575-586. [CrossRef]

12. Panhwar, M.S.; Kalra, A.; Gupta, T.; Kolte, D.; Khera, S.; Bhatt, D.; Ginwalla, M. Relation of Concomitant Heart Failure to Outcomes in Patients Hospitalized With Influenza. Am. J. Cardiol. 2019, 123, 1478-1480. [CrossRef]

13. Sandoval, C.; Walter, S.D.; Krueger, P.; Loeb, M.B. Comparing estimates of influenza-associated hospitalization and death among adults with congestive heart failure based on how influenza season is defined. BMC Public Health 2008, 8, 59. [CrossRef] [PubMed]

14. Sandoval, C.; Walter, S.D.; Krueger, P.; Smieja, M.; Smith, A.; Yusuf, S.; Loeb, M.B. Risk of hospitalization during influenza season among a cohort of patients with congestive heart failure. Epidemiol. Infect. 2007, 135, 574-582. [CrossRef]

15. Visseaux, B.; Burdet, C.; Voiriot, G.; Lescure, F.X.; Chougar, T.; Brugiere, O.; Crestani, B.; Casalino, E.; Charpentier, C.; Descamps, D.; et al. Prevalence of respiratory viruses among adults, by season, age, respiratory tract region and type of medical unit in Paris, France, from 2011 to 2016. PLoS ONE 2017, 12, e0180888. [CrossRef] [PubMed]

16. Ivey, K.S.; Edwards, K.M.; Talbot, H.K. Respiratory Syncytial Virus and Associations With Cardiovascular Disease in Adults. J. Am. Coll. Cardiol. 2018, 71, 1574-1583. [CrossRef]

17. Harling, R.; Hayward, A.; Watson, J.M. Implications of the incidence of influenza-like illness in nursing homes for influenza chemoprophylaxis: Descriptive study. BMJ 2004, 329, 663-664. [CrossRef] [PubMed]

18. Pieske, B.; Tschope, C.; de Boer, R.A.; Fraser, A.G.; Anker, S.D.; Donal, E.; Edelmann, F.; Fu, M.; Guazzi, M.; Lam, C.S.P.; et al. How to diagnose heart failure with preserved ejection fraction: The HFA-PEFF diagnostic algorithm: A consensus recommendation from the Heart Failure Association (HFA) of the European Society of Cardiology (ESC). Eur. Heart J. 2019, 40, 3297-3317. [CrossRef] [PubMed]

19. Federal Office of Public Health. Seasonal Flu (Influenza). Available online: https://www.bag.admin.ch/bag/en/home/begriffea-z/saisonale-grippe (accessed on 24 April 2020).

20. Carballo, S.; Musso, P.; Garin, N.; Muller, H.; Serratrice, J.; Mach, F.; Carballo, D.; Stirnemann, J. Prognostic Value of the Echocardiographic Probability of Pulmonary Hypertension in Patients with Acute Decompensated Heart Failure. J. Clin. Med. 2019, 8, 1684. [CrossRef] [PubMed]

21. Glezen, W.P.; Greenberg, S.B.; Atmar, R.L.; Piedra, P.A.; Couch, R.B. Impact of respiratory virus infections on persons with chronic underlying conditions. JAMA 2000, 283, 499-505. [CrossRef]

22. Thompson, W.W.; Shay, D.K.; Weintraub, E.; Brammer, L.; Cox, N.; Anderson, L.J.; Fukuda, K. Mortality associated with influenza and respiratory syncytial virus in the United States. JAMA 2003, 289, 179-186. [CrossRef]

23. Jain, S.; Self, W.H.; Wunderink, R.G.; Fakhran, S.; Balk, R.; Bramley, A.M.; Reed, C.; Grijalva, C.G.; Anderson, E.J.; Courtney, D.M.; et al. Community-Acquired Pneumonia Requiring Hospitalization among U.S. Adults. N. Engl. J. Med. 2015, 373, 415-427. [CrossRef]

24. Musher, D.M.; Roig, I.L.; Cazares, G.; Stager, C.E.; Logan, N.; Safar, H. Can an etiologic agent be identified in adults who are hospitalized for community-acquired pneumonia: Results of a one-year study. J. Infect. 2013, 67, 11-18. [CrossRef] [PubMed]

25. Musher, D.M.; Rueda, A.M.; Kaka, A.S.; Mapara, S.M. The association between pneumococcal pneumonia and acute cardiac events. Clin. Infect. Dis. 2007, 45, 158-165. [CrossRef] [PubMed]

26. Kwong, J.C.; Schwartz, K.L.; Campitelli, M.A.; Chung, H.; Crowcroft, N.S.; Karnauchow, T.; Katz, K.; Ko, D.T.; McGeer, A.J.; McNally, D.; et al. Acute Myocardial Infarction after Laboratory-Confirmed Influenza Infection. N. Engl. J. Med. 2018, 378, 345-353. [CrossRef] 
27. Panhwar, M.S.; Kalra, A.; Gupta, T.; Kolte, D.; Khera, S.; Bhatt, D.L.; Ginwalla, M. Effect of Influenza on Outcomes in Patients with Heart Failure. JACC Heart Fail. 2019, 7, 112-117. [CrossRef] [PubMed]

28. Falsey, A.R.; Hennessey, P.A.; Formica, M.A.; Cox, C.; Walsh, E.E. Respiratory syncytial virus infection in elderly and high-risk adults. N. Engl. J. Med. 2005, 352, 1749-1759. [CrossRef]

29. Lee, N.; Lui, G.C.; Wong, K.T.; Li, T.C.; Tse, E.C.; Chan, J.Y.; Yu, J.; Wong, S.S.; Choi, K.W.; Wong, R.Y.; et al. High morbidity and mortality in adults hospitalized for respiratory syncytial virus infections. Clin. Infect. Dis. 2013, 57, 1069-1077. [CrossRef]

30. Iversen, K.K.; Kjaergaard, J.; Akkan, D.; Kober, L.; Torp-Pedersen, C.; Hassager, C.; Vestbo, J.; Kjoller, E.; Group, E.C.-L.F.S. Chronic obstructive pulmonary disease in patients admitted with heart failure. J. Intern. Med. 2008, 264, 361-369. [CrossRef]

31. Rusinaru, D.; Saaidi, I.; Godard, S.; Mahjoub, H.; Battle, C.; Tribouilloy, C. Impact of chronic obstructive pulmonary disease on long-term outcome of patients hospitalized for heart failure. Am. J. Cardiol. 2008, 101, 353-358. [CrossRef]

32. Hawkins, N.M.; Virani, S.; Ceconi, C. Heart failure and chronic obstructive pulmonary disease: The challenges facing physicians and health services. Eur. Heart J. 2013, 34, 2795-2803. [CrossRef]

33. Aronson, D.; Darawsha, W.; Atamna, A.; Kaplan, M.; Makhoul, B.F.; Mutlak, D.; Lessick, J.; Carasso, S.; Reisner, S.; Agmon, Y.; et al. Pulmonary hypertension, right ventricular function, and clinical outcome in acute decompensated heart failure. J. Card. Fail. 2013, 19, 665-671. [CrossRef] [PubMed]

34. Tisdale, R.L.; Haddad, F.; Kohsaka, S.; Heidenreich, P.A. Trends in Left Ventricular Ejection Fraction for Patients With a New Diagnosis of Heart Failure. Circ. Heart Fail. 2020, 13, e006743. [CrossRef] [PubMed]

35. Zurcher, K.; Zwahlen, M.; Berlin, C.; Egger, M.; Fenner, L. Trends in influenza vaccination uptake in Switzerland: Swiss Health Survey 2007 and 2012. Swiss Med. Wkly. 2019, 149, w14705. [CrossRef] [PubMed]

36. Salez, N.; Vabret, A.; Leruez-Ville, M.; Andreoletti, L.; Carrat, F.; Renois, F.; de Lamballerie, X. Evaluation of Four Commercial Multiplex Molecular Tests for the Diagnosis of Acute Respiratory Infections. PLoS ONE 2015, 10, e0130378. [CrossRef] 